\title{
A descriptive epidemiological study of cardiovascular diseases among seafarers
}

\author{
Getu Gamo Sagaro ${ }^{1}(1)$, Gopi Battineni $^{1}{ }^{\oplus}$, Marzio Di Canio $^{1,2}\left({ }^{10}\right.$, \\ Andrea Minciacchi ${ }^{2}$, Giulio Nittari ${ }^{1}\left(\mathbb{D}\right.$, Francesco Amenta $^{1,2}$ (D) \\ ${ }^{1}$ Telemedicine and Telepharmacy Centre, School of Medicinal and Health Products Sciences, University of Camerino, Italy \\ ${ }^{2}$ Research Department, International Radio Medical Centre (C.I.R.M.), Rome, Italy
}

\begin{abstract}
Background: Cardiovascular diseases (CVD) are the leading cause of morbidity and mortality among seafarers. This study aimed to evaluate CVDs distribution and differences, considering seafarers' rank and worksite groups.

Materials and methods: A descriptive epidemiological study was employed, and the analysis was based on the telemedical assistance data of the International Radio Medical Centre (C.I.R.M.) from 2010 to 2018. The age, gender, rank, and worksite variables were considered for the analysis. Chi-square or Fisher test was used to assess differences in CVD distribution between rank and worksite groups.

Results: Cardiovascular diseases were the sixth leading cause of medical advice requests to C.I.R.M. Distribution of CVD significantly differed between officers and non-officers $\left[x^{2}(5)=17.308, p=0.004\right]$. Officers were often diagnosed with hypertensive CVD (46\%), whereas non-officers were frequently diagnosed with ischaemic heart diseases (41\%). There were no significant differences in the distribution of CVD diagnoses between worksite groups $\left[x^{2}(10)=12.863, p=0.231\right]$.

Conclusions: The frequency of CVD is higher among non-officers and older seafarers who have been more often diagnosed with CVD. Specific interventions such as early diagnosis, regular monitoring, and physical training to reduce cardiovascular risk should be considered on board ships. Future studies should take into account the incidence rate of CVD between rank and worksite groups.
\end{abstract}

(Int Marit Health 2021; 72, 4: 252-258)

Key words: cardiovascular diseases, epidemiology, seafarers, hypertensive disease, ischaemic heart disease

\section{INTRODUCTION}

Cardiovascular diseases (CVD) are the term defining several pathologies affecting the cardiovascular system. These include coronary heart disease, cerebrovascular disease, peripheral arterial disease, rheumatic and congenital heart diseases, and venous thromboembolism [1]. CVD is the leading cause of death worldwide, with approximately 17.9 million people dying per year and representing 31\% of all global deaths. Of these deaths, about 7.4 million and 6.7 million were due to coronary heart disease and stroke, respectively [2]. In 2015, more than 1.6 million sea- farers were employed worldwide, of which approximately 775,000 and 875,000 were officers and ratings, respectively [3]. In general, nautical work is broadly grouped by working place on board ships, including deck, engine, and galley [4], based on the differences between professional duties on board. CVD is the number one cause of death among seafarers, and the mortality rates on board are higher than those observed on shore [5-7]. Workers at sea have high mortality, injuries, and illnesses, probably as a consequence that they are working in hazardous environments.

Dr. Getu Gamo Sagaro, Telemedicine and Telepharmacy Centre, School of Medicinal and Health Products Sciences, University of Camerino, Via Madonna Delle Carceri 9 ,

62032 Camerino MC, Italy, e-mail: getugamo.sagaro@unicam.it 
Different studies revealed that modifiable lifestyles such as tobacco use, harmful use of alcohol, physical inactivity, and unhealthy diet together with other significant risk factors, including increased arterial pressure, blood glucose levels, elevated blood lipids, overweight, and obesity, are the most critical. The above risk factors are causally linked with CVD, which represent the leading causes of deaths and disability in most countries [8-13]. Overweight and obesity represent relevant CVD risk factors for seafarers, and in these workers occur more often than in the general population [14]. A study conducted on the board of Italian flagship (2019) reported that more than $40 \%$ and $10 \%$ of seafarers were overweight and obese, respectively [15]. Another work on Iranian seafarers revealed that overweight increased from $46.7 \%$ to $60.9 \%$ over the period of 3 years [16]. These results indicate that in seafarers' CVD risk factors become worse compared to ashore workers. Other risk factors like gender, stress, depression and age are causes of CVD, and the reduction of these risk factors decreases the burden of CVD in all age groups [17]. Mental, psychological, and physical stressors represent other factors influenced by work-related issues [18]. These include isolation from family, long working hours, lack of shore leave, fatigue, exposure to different unhealthy lifestyles, and others [18-23] and make seafarers at a higher risk of CVD than the general population.

Ischaemic heart disease (IHD) and stroke are the principal components of the CVD burden globally and contributed to approximately 15.2 million deaths in 2015 [24, 25]. This accounts for more than $85 \%$ of all deaths due to CVD in the same year [24]. IHD and stroke cases increased, from 7.3 to 8.93 million and from 5.29 to 6.17 million deaths, respectively, between 2007 and 2017 [26]. The incidence and mortality rate of IHD has decreased in high-income countries in the last 25 years [25, 27, 28]. In contrast, the prevalence and mortality rate for this pathology is increased remarkably with age in developing countries and Eastern Europe [25, 27]. This suggests that CVD is reversing in developed countries and needs more attention in developing countries [26].

To meet the global health policy goal of reducing CVDs, further analysis of epidemiological data focusing on location, age, and time patterns is important [26]. This is because countering risk factors represents a health target in sustainable development goals for CVD reduction [25, 29]. In addition, the global efforts to reduce the CVD burden should be evidence-based [25] and centred on analysing the prevalence trends of these disorders.

Cardiovascular disease needs attention in commercial maritime operations because a high proportion of CVD death rate was recorded at sea among sailing seafarers [30-33]. Moreover, seafarers are exposed to different work-related stressors and potential complications like the risk of sudden cardiac arrest. In view of this, studies should provide evidence-based information about the CVD burden in the case of seafarers to handle events effectively [6].

The present work has evaluated the CVD distribution and differences between the rank and the seafarers' worksite. The analysis was made based on medical assistance data to seafarers provided by Centro Internazionale Radio Medico (International Radio Medical Centre, C.I.R.M.), the Italian Telemedical Maritime Assistance Service (TMAS).

\section{MATERIALS AND METHODS}

A descriptive epidemiological study was used to evaluate the distribution and differences in CVD occurrence between occupational groups and seafarers' worksites from 2010 to 2018.

\section{DATA SOURCE AND COLLECTION PROCEDURES}

Data were obtained from the C.I.R.M. database. C.I.R.M. is a non-profit institution established in 1935 which provides worldwide telemedical assistance to sailing seafarers [34]. The Centre was appointed in 2002 as the Italian TMAS and is the type of organization with the largest experience worldwide in terms of the number of patients assisted on board ships. For the last 84 years (from April 1935 to December 2019), the C.I.R.M. assisted more than 101,600 patients' on board ships and received 686,163 calls for medical consultations, with an average of 6 calls per patient. Data of C.I.R.M. assistance are available for each year with their gender, age, country, duties, and the diagnosis was encoded by both World Health Organization (WHO) International Classification of Diseases (ICD) $9^{\text {th }}$ and ICD $10^{\text {th }}$ versions. We used for this study data from 2010 to 2018 because, until 2009 , data were encoded by ICD $9^{\text {th }}$ version, but we considered 2010 and onwards data in which diagnoses were classified according to the ICD $10^{\text {th }}$ version. In this version, the cardiovascular disease ICD code is from I00-199. Diseases affecting seafarers were therefore classified into IHD (I20-I25), hypertensive disease (I10-I15), acute rheumatic fever (I00-102), chronic rheumatic heart disease (I05-109), pulmonary heart disease, and diseases of pulmonary circulation (I26-128). Other forms of heart disease (130-152), cerebrovascular disease (160-169), diseases of arteries, arterioles, and capillaries (170-179), diseases of veins, lymphatic vessels, and lymph nodes, not elsewhere classified (180-189) and unspecified disorders of the circulatory system (195-199) [35] were also considered.

All recorded medical data are stored in the C.I.R.M. database, which is not accessible for externals. Data extraction, compiling, and coding were then performed. The attributes collected from each diagnosis were age, gender, occupational rank, and worksite. Age was cal- 
culated by subtracting the seafarer's date of birth from the date of medical advice provision. Seafarers, the date of birth of which was not available, were excluded from this study.

\section{STATISTICAL ANALYSIS}

Descriptive analysis of seafarers' demographic variables, including age, gender, rank, and worksite, was done to evaluate the distribution of CVDs. Quantitative attributes like age and sex were encoded and categorized. For example, the age of seafarers was categorized into five groups: less than or equal to 30 years (age group 1), 31-40 years (age group 2), 41-50 years (age group 3), 51-60 years (age group 4) and older than 60 years (age group 5). Occupational rank was stratified by officers (deck and engine officers) and non-officers (deck and engine ratings, and galley), whereas worksites were categorized into three groups, namely deck, engine, and galley. Chi-square or Fisher's exact test was used to analyse distributional differences in rank and worksite groups. Data analysis was made using the IBM SPSS Statistics software version 26.

\section{RESULTS \\ DEMOGRAPHIC CHARACTERISTICS}

Overall, 1,377 CVD cases were assisted by C.I.R.M. during the 9 years under study. Almost all (98\%) seafarers examined with CVD were male, and the average age ( \pm standard deviation) of the patients with CVDs was $48.35 \pm 12.71$ years. CVD was frequently diagnosed in seafarers aged $51-60$ years (31\% of all seafarers with CVD). CVD occurred more often in non-officers compared to officers (748 [54.3\%] vs. 629 [45.7\%]) and was almost 2 and 9 times more frequent in the deck than in the engine and galley workers (Table 1).

Cardiovascular disease was the sixth leading cause for accessing the C.I.R.M. Other cases such as gastrointestinal disease and injury/trauma were the first and second most frequent causes of pathologies assisted among seafarers and accounted for 5,372 (16.60\%) and $5,330(16.40 \%)$ of all medical events, respectively, during the study period (Fig. 1).

The frequencies of different CVD diagnoses are shown in Figure 2. The most frequent CVD were hypertensive diseases $(n=551 ; 40 \%)$ and IHD $(n=530 ; 38.5 \%)$. Among hypertensive diseases, arterial hypertension was the most frequently diagnosed ( $89 \%$ of the total hypertensive diseases), whereas other types of hypertensive diseases such as hypertensive heart disease, renal diseases, and secondary hypertension accounted for $11 \%$ of the total hypertensive diseases. IHD included unspecified angina pectoris (376 cases), acute myocardial infarction (132 cases), and other forms of angina pectoris (22 cases).
Table 1. Demographic characteristics of seafarers with cardiovascular disease from 2010 to 2018

\begin{tabular}{lll}
\hline Variable & $\begin{array}{l}\text { Number of cases } \\
(\mathbf{n}=\mathbf{1 , 3 7 7})\end{array}$ & Frequency (\%) \\
\hline Age group & & 9.7 \\
$\leq 30$ & 133 & 16.8 \\
$31-40$ & 231 & 28 \\
$41-50$ & 385 & 31 \\
$51-60$ & 429 & 14.5 \\
$>60$ & 199 & \\
Mean (SD) & $48.35 \pm 12.71$ & \\
Gender & & 98 \\
Male & 1,345 & 2 \\
Female & 32 & \\
Rank & & 45.7 \\
Officer & 629 & 54.3 \\
Non-officer & 748 & \\
Worksite & & 59 \\
Deck & 807 & 65 \\
Engine & 479 & \\
Galley & 91 & \\
SD - standard deviation &
\end{tabular}

The other heart disease forms were the third most often diagnosed CVD, accounting for approximately $7 \%$ (95) of pathologies of this group. A common diagnosis of other forms of heart disease included cardiac arrest (62 cases), paroxysmal tachycardia (26 cases), and other cardiac arrhythmias (7 cases). Cerebrovascular diseases were also diagnosed in 59 seafarers and accounted for over $4 \%$ of total CVD. The most often cerebrovascular diagnosis included stroke, which is responsible for $80 \%$ of total cerebrovascular cases. Cerebral infarction accounted for the remaining 20\% of cerebrovascular diseases.

Diseases of veins and lymphatic vessels were responsible for nearly $4 \%(50)$ of medical advice requests received. $91 \%$ of these pathologies included phlebitis and thrombophlebitis. The remaining $9 \%$ consisted of portal vein thrombosis and varicose veins of other sites.

\section{DIFFERENCES BETWEEN OFFICERS AND NON-OFFICERS IN CVD DISTRIBUTION}

The average age of officers and non-officers with CVD was $48.21 \pm 13.08$ years and $48.47 \pm 12.44$ years, respectively. CVD was frequently diagnosed in officers aged 41 to 50 years and in non-officers aged 51 and 60 years during the study period (Fig. 3).

Officers were frequently diagnosed with hypertensive CVDs (46\%), whereas non-officers were often diagnosed 


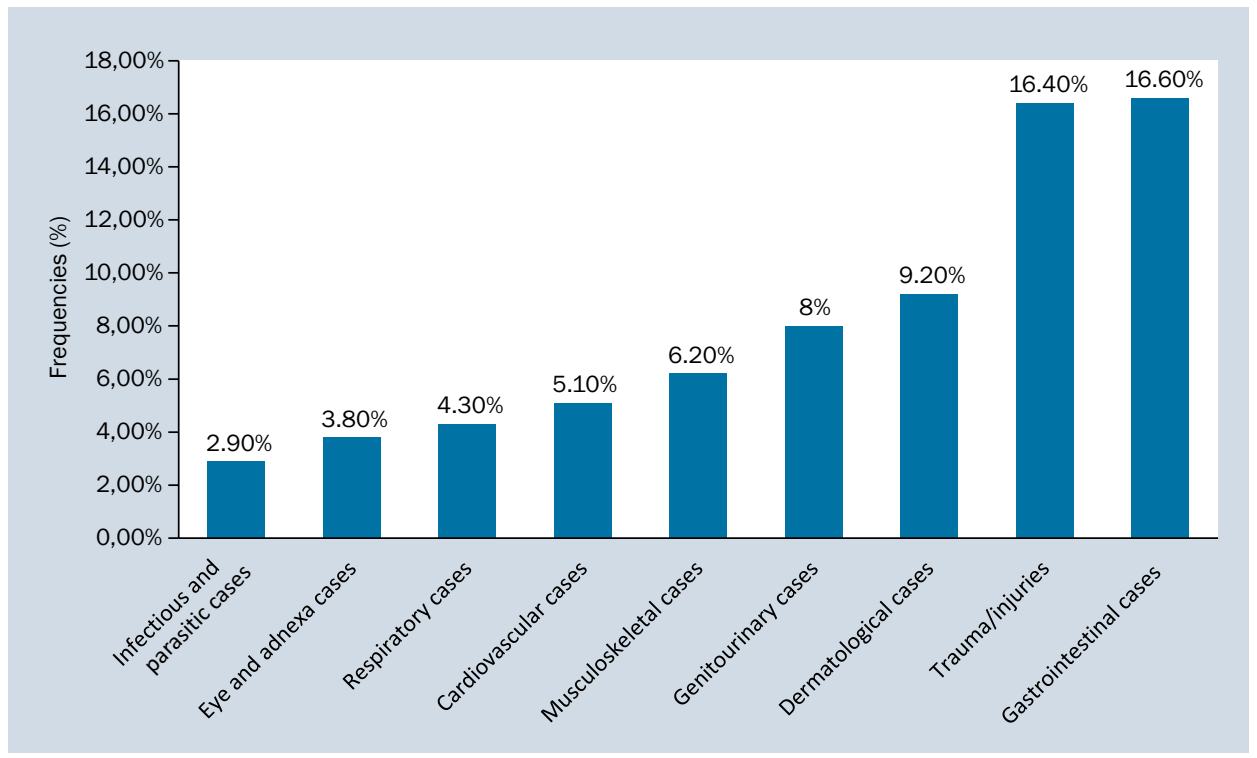

Figure 1. Frequencies (\%) of pathologies assisted by Centro Internazionale Radio Medico (International Radio Medical Centre, C.I.R.M.) from 2010 to 2018

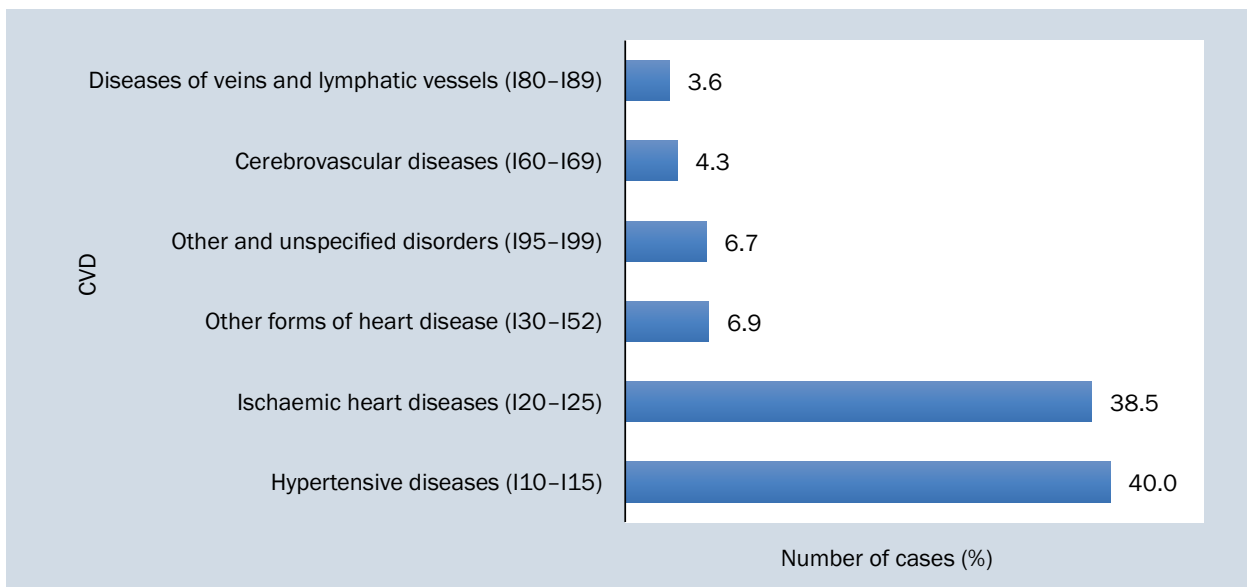

Figure 2. Frequencies (\%) of cardiovascular diseases (CVD) diagnosis according to World Health Organization (WHO) International Classification of Diseases (ICD) $10^{\text {th }}$ category from 2010 to $2018(n=1,377)$

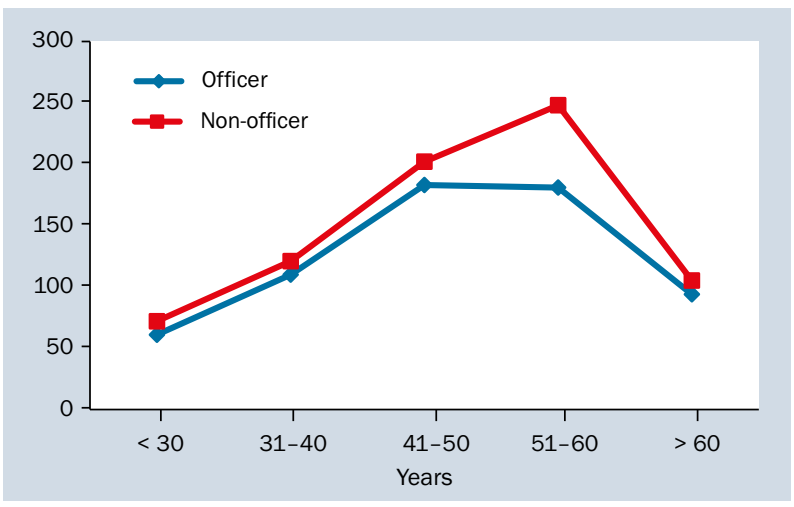

Figure 3. Distribution of cardiovascular diseases by age group between officers and non-officers with cardiovascular cases from 2010 to 2018 with IHDs (41\%). The observed frequencies and percentages of each type of CVD diagnosis by seafarer rank are summarised in Table 2. The distribution of CVD diagnosis between officers and non-officers was significantly different $\left[x^{2}(5)=17.308, p=0.004\right]$ (Table 2).

\section{DISTRIBUTIONS OF CVD BETWEEN WORKSITE GROUPS ONBOARD SHIPS}

We found that deck workers were often diagnosed with IHD (41.9\%), while engine room workers (43.8\%) and galley (46.2\%) were frequently diagnosed with hypertensive diseases. There was no difference in distribution of CVD diagnosis between worksite groups $\left[x^{2}(10)=12.863\right.$, $p=0.231]$ (Table 3). 
Table 2. Distribution of cardiovascular diseases by seafarer rank from 2010 to 2018 ( $n=1,377$ )

\begin{tabular}{llll}
\hline Types of cardiovascular diseases & Rank & P-value \\
\cline { 2 - 3 } & Officer & Non-officer & 0.004 \\
\hline Total & $629(100)$ & $748(100)$ & $263(35 \%)$ \\
Hypertensive diseases (I10-I15) & $288(46 \%)$ & $310(41 \%)$ \\
Ischaemic heart diseases (I20-I25) & $220(35 \%)$ & $56(7 \%)$ \\
Other forms of heart disease (I30-152) & $39(6 \%)$ & $38(5 \%)$ \\
Cerebrovascular diseases (I60-169) & $21(3 \%)$ & $27(4 \%)$ \\
Diseases of veins and lymphatic vessels (180-189) & $23(4 \%)$ & $54(7 \%)$ \\
Other and unspecified disorders (I95-199) & $38(6 \%)$ &
\end{tabular}

Table 3. Distribution of cardiovascular diseases by seafarer worksites from 2010 to $2018(n=1,377)$

\begin{tabular}{lllll}
\hline Types of cardiovascular diseases & Worksites & & \multicolumn{2}{c}{ P-value } \\
\cline { 2 - 4 } & Deck & Engine & Galley & 0.231 \\
\hline Total & $807(100 \%)$ & $479(100 \%)$ & $91(100 \%)$ & $42(46.2 \%)$ \\
Hypertensive diseases (I10-I15) & $299(37 \%)$ & $210(43.8 \%)$ & $30(32.9 \%)$ \\
Ischaemic Heart diseases (I20-I25) & $338(41.9 \%)$ & $162(33.8 \%)$ & $35(7.3 \%)$ & $6(6.6 \%)$ \\
Other forms of heart disease (I30-152) & $54(6.7 \%)$ & $20(4.2 \%)$ & $3(3.3 \%)$ \\
Cerebrovascular diseases (160-169) & $36(4.5 \%)$ & $15(3.2 \%)$ & $3(3.3 \%)$ \\
Diseases of veins and lymphatic vessels (180-189) & $32(3.9 \%)$ & $37(7.7 \%)$ & $7(7.7 \%)$ \\
Other and unspecified disorders (195-199) & $48(5.9 \%)$ & &
\end{tabular}

\section{DISCUSSION}

Over 9 years (from 2010 to 2018), there were 1,377 contacts to C.I.R.M due to CVD. Among the medical advice requests, $40 \%$ and $38.5 \%$ were respectively for hypertensive and IHD. The remaining $21.5 \%$ were for other heart disease forms, cerebrovascular diseases, diseases of veins and lymphatic vessels, and unspecified disorders of the circulatory system. In this study, we focused on the distribution and differences of CVD between the rank and the seafarers' worksite groups based on the assistance data of C.I.R.M. This type of analysis was chosen for practical reasons because it is difficult to estimate the incidence of CVD among seafarers without information on the total at-risk seafarer population on board ships.

In this study, we found that CVD was the sixth leading cause of accessing C.I.R.M. medical services. These results are not consistent with a German study [36] but in line with research conducted in the United States merchant vessels [6]. Nevertheless, these diseases are critical and one of the main health problems for seafarers. This is because factors such as exposure to the noise, job strain, and fatigue could increase CVD risk among seafarers. On the other hand, seafarers stay for long times away from their families, and they are experiencing many work-related is- sues such as physical, mental, and psychological stressors that can exacerbate the risk of developing CVD. Another study conducted on seafarers reported that vessel-specific stress, unhealthy diet, and lack of exercise were the major risk factor for CVD on board. This could be the reason for the not negligible occurrence of CVD among seafarers [38] in spite of the rather frequent cardiovascular pre-employment tests that people working at sea should make every 2 years. A study conducted in the modern maritime industry reported several work-related cardiac risk factors such as time pressure, long working hours, and high-stress factors are present on board [37].

The present study has shown that CVD distribution between officers and non-officers was significantly different $\left[x^{2}(5)=17.308, p=0.004\right]$, with non-officers having more CVD diagnoses than officers. This may be due to differences in stress management, lifestyle risk factors, and high work-related stressors. In addition, a recently conducted study among seafarers revealed that non-officers required a high level of physical effort to carry out their duties, and they had a higher risk of psychological stress than officers because of work-related risk factors [38]. This may explain our findings of different frequencies of CVD diagnoses between officers and non-officers. In contrast, 
no significant differences in CVD diagnosis by seafarer's worksite were noticeable.

In this study, hypertensive disease was the most common CVD, accounting for $40 \%$ of all cardiovascular cases. Arterial hypertension with $89 \%$ of diagnoses was the main CVD affecting seafarers. A Danish study revealed that arterial hypertension was the main health concern of seafarers. The same study reported $44.7 \%$ and $41.8 \%$ of the prevalence of hypertension and pre-hypertension, respectively, among Danish seafarers [39]. According to different studies, the prevalence of CVD was increased among seafarers because of unhealthy lifestyles such as smoking, a high-fat diet, and inadequate physical activity [36]. This may explain our findings of the elevated frequency of hypertensive disease diagnoses. Ischaemic heart disease was the second most frequent disorder in the present work, accounting for 39\% of all cardiovascular diseases. The basic medical assistance level that can be offered to on board ships without doctors or adequately trained paramedics, complicated by the relevant limitations in terms of availability of diagnostic devices on board, makes our analysis rather generic. For instance, situations like unspecified angina pectoris would need additional tests to confirm the condition, but unfortunately, this is not possible in the large majority of merchant ships $[6,40]$. Moreover, devices for precise CVD diagnoses such as electrocardiogram, echocardiogram, coronary angiogram, and myocardial imaging to minimise misdiagnosis and prevent treatment delay remain today a dream far becoming a reality. Despite the above limitations, our analysis, based on requests coming from the ship side at the time of occurrence of symptoms requiring medical care, represents a real-life survey of what happens in an isolated environment like a ship in the middle of the sea.

The present study showed that CVD frequently occurred in older seafarers on board, with 31\% (429) of all CVD cases affecting people aged between 51 to 60 years. In other words, the distribution of CVD among older seafarers is threefold higher than in younger seafarers (less than or equal to 30 years). Our results are in line with those of a German study reporting that CVD distribution significantly varied between age groups among seafarers [36]. In other words, as expected, increasing age is associated with a higher likelihood of CVD. This observation should consider more deep fitting tests in older seafarers and an effective preventative measure targeting older age seafarers on board.

\section{LIMITATIONS OF THE STUDY}

This study has some limitations and strengths. It was a retrospective descriptive study, and in nature, it has its constraints, including variable incomplete. Other limitations are gender disproportion and not considering the nationality variable because these attributes for some seafarers were incomplete in the database. We have also not assessed the incidence rate or cumulative incidence because of the lack of control group data. However, this study has some strengths. This work has shown the case frequency and differences between occupational groups. This can give insights into cardiovascular problems' real occurrence and stimulate future incidence of CVD studies in merchant seafarers.

\section{CONCLUSIONS}

Non-officers had a higher frequency of CVD diagnosis compared to officers during the study period. Officers were frequently diagnosed with hypertensive CVDs, whereas non-officers often diagnosed with IHDs. Older seafarers aged 51 to 60 were the age group with a higher frequency of CVD. To prevent CVD distribution and reduce their burden on merchant seafarers, effective prevention measures such as early diagnosis, regular follow-up, and training crewmembers on basic life support and using automatic external defibrillators should be considered. In addition, telemonitoring equipment for cardiovascular diagnosis via telemedicine should be introduced on a large scale on board to guarantee higher quality medical assistance to sailing seafarers. Special attention should also be given to seafarers older than 50 years. Primary prevention focused on increased awareness of CVD risk factors, intensive health education campaigns, and regular medical check-ups on board should be considered with full attention.

\section{FUNDING SOURCE AND ACKNOWLEDGEMENTS}

The present study is part of an epidemiological analysis carried out in the frame of a project supported by the ITF Seafarers' Trust grant No. 1276/2018 to develop an intelligent system for improving medical assistance seafarers.

\section{Conflict of interest: None declared}

\section{REFERENCES}

1. World Health Organization, "Cardiovascular diseases (CVDs)," 2016. [Online]. https://www.who.int/en/news-room/fact-sheets/detail/ cardiovascular-diseases-(cvds) (Accessed: 28-Mar-2019).

2. World Health Organization, "Cardiovascular Disease (CVD)," 2017. [Online]. https://www.who.int/news-room/fact-sheets/detail/cardiovascular-diseases-(cvds) (Accessed: 28-Mar-2019).

3. B.I.M.C.O. and I.C.S. Manpower Report-The global supply and demand for seafarers. Exec. Summ, 2015, p. 6.

4. Lefkowitz RY, Slade MD, Redlich CA. Injury, illness, and disability risk in American seafarers. Am J Ind Med. 2018; 61(2): 120-129, doi: 10.1002/ajim.22802, indexed in Pubmed: 29250811.

5. Oldenburg M, Herzog J, Harth V. Seafarer deaths at sea: a German mortality study. Occup Med (Lond). 2016; 66(2): 135-137, doi: 10.1093/occmed/kqv153, indexed in Pubmed: 26409049.

6. Alves PM, Leigh R, Bartos G, et al. Cardiovascular events on board commercial maritime vessels: a two-year review. Int Marit Health. 2010; 62(3): 137-142, indexed in Pubmed: 21154300. 
7. Grappasonni I, Petrelli F, Amenta F. Deaths on board ships assisted by the Centro Internazionale Radio Medico in the last 25 years. Travel Med Infect Dis. 2012; 10(4): 186-191, doi: 10.1016/j. tmaid.2012.06.006, indexed in Pubmed: 22819258.

8. Buring JE, Hennekens $\mathrm{CH}$. Prevention of cardiovascular disease: risks and benefits of aspirin. J Gen Intern Med. 1990; 5(5 Suppl): S54-S57, doi: 10.1007/BF02600843, indexed in Pubmed: 2231066.

9. Yang ZJ, Liu J, Ge JP, et al. Prevalence of cardiovascular disease risk factor in the Chinese population: the 2007-2008 China National Diabetes and Metabolic Disorders Study. Eur Heart J. 2012; 33(2): 213-220, doi: 10.1093/eurheartj/ehr205, indexed in Pubmed: 21719451.

10. Rabani S, Sardarinia M, Akbarpour S, et al. 12-year trends in cardiovascular risk factors (2002-2005 through 2011-2014) in patients with cardiovascular diseases: Tehran lipid and glucose study. PLoS One. 2018; 13(5): e0195543, doi: 10.1371/journal.pone.0195543, indexed in Pubmed: 29768511.

11. Konings JWPM, Caliskan K, Balk AHHM, et al. Complexe revalidatie van een jongvolwassen patiënt: Niedaags, wel mogelijk Tijdschr. Tijdschr. voor Verpleeghuisgeneeskd. 2008; 33(4): 130-133, doi: 10.1161/CIR.0000000000000558.

12. Schweigman K, Eichner J, Welty TK. Cardiovascular disease risk factor awareness in American Indians to assess awareness of nine diseases among participants in the Strong Heart Study (S.H.S.). Ethnicity. 2006; 16: 2006.

13. Yusuf S, Reddy S, Ôunpuu S, et al. Global burden of cardiovascular diseases. Circulation. 2001; 104(22): 2746-2753, doi: 10.1161/ hc4601.099487.

14. Szafran-Dobrowolska J, Renke M, Jeżewska M. Is it worth to continue to analyse the factors of cardiovascular risk among the sailors? Review of literature. Int Marit Health. 2019; 70(1): 17-21, doi: 10.5603/IMH.2019.0003, indexed in Pubmed: 30931513.

15. Nittari G, Tomassoni D, Di Canio M, et al. Overweight among seafarers working on board merchant ships. BMC Public Health. 2019; 19(1): 45, doi: 10.1186/s12889-018-6377-6, indexed in Pubmed: 30626365.

16. Baygi F, Jensen OC, Qorbani M, et al. Pattern of some risk factors of cardiovascular diseases and liver enzymes among Iranian seafarers. Med J Islam Repub Iran. 2017; 31: 23, doi: 10.18869/mjiri.31.23, indexed in Pubmed: 29445652.

17. Heart Foundation. Cardiovascular disease Factsheet. 2013, vol. 6, no. Cvd, pp. 138-141.

18. Carotenuto A, Molino I, Fasanaro AM, et al. Psychological stress in seafarers: a review. Int Marit Health. 2012; 63(4): 188-194, indexed in Pubmed: 24595974.

19. Allen P, Wadsworth E, Smith A. Seafarers' fatigue: a review of the recent literature. Int Marit Health. 2008; 59(1-4): 81-92, indexed in Pubmed: 19227741.

20. Iversen RTB. The mental health of seafarers. Int Marit Health. 2012; 63(2): 78-89, indexed in Pubmed: 22972547.

21. MacLachlan M, Kavanagh B, Kay A. Maritime health: a review with suggestions for research. Int Marit Health. 2012; 63(1): 1-6, indexed in Pubmed: 22669806.

22. Oldenburg $M$, Baur X, Schlaich C. Occupational risks and challenges of seafaring. J Occup Health. 2010; 52(5): 249-256, doi: 10.1539/ joh.k10004, indexed in Pubmed: 20661002.

23. Slišković A, Penezić Z. Occupational stressors, risks and health in the seafaring population. Rev Psychol. 2016; 22(1-2): 29-39, doi: 10.21465/rp0022.0004.
24. Wang $\mathrm{H}$, Naghavi $\mathrm{M}$, Allen $\mathrm{C}$, et al. Global, regional, and national life expectancy, all-cause mortality, and cause-specific mortality for 249 causes of death, 1980-2015: a systematic analysis for the Global Burden of Disease Study 2015. Lancet. 2016; 388(10053): 1459-1544, doi: 10.1016/s0140-6736(16)31012-1.

25. Joseph $P$, Leong $D$, McKee $M$, et al. Reducing the global burden of cardiovascular disease. Part 1: the epidemiology and risk factors. Circ Res. 2017; 121(6): 677-694, doi: 10.1161/CIRCRESAHA.117.308903, indexed in Pubmed: 28860318.

26. Roth G, Abate D, Abate K, et al. Global, regional, and national age-sex-specific mortality for 282 causes of death in 195 countries and territories, 1980-2017: a systematic analysis for the Global Burden of Disease Study 2017. Lancet. 2018; 392(10159): 1736-1788, doi: 10.1016/s0140-6736(18)32203-7.

27. Moran AE, Forouzanfar MH, Roth GA, et al. The global burden of ischemic heart disease in 1990 and 2010: the Global Burden of Disease 2010 study. Circulation. 2014; 129(14): 1493-1501, doi: 10.1161/ CIRCULATIONAHA.113.004046, indexed in Pubmed: 24573351.

28. Moran AE, Forouzanfar MH, Roth GA, et al. Temporal trends in ischemic heart disease mortality in 21 world regions, 1980 to 2010: the Global Burden of Disease 2010 study. Circulation. 2014; 129(14): 1483-1492, doi: 10.1161/CIRCULATIONAHA.113.004042, indexed in Pubmed: 24573352.

29. Go A, Mozaffarian D, Roger V, et al. Executive summary: heart disease and stroke statistics - 2014 update. Circulation. 2014; 129(3): 399-410, doi: 10.1161/01.cir.0000442015.53336.12.

30. Roberts SE. Mortality from disease among seafarers in British merchant shipping (1976-1995). Int Marit Health. 2002; 53(1-4): 43-58, indexed in Pubmed: 12608588.

31. Hansen HL. Surveillance of deaths on board Danish merchant ships, 1986-93: implications for prevention. Occup Environ Med. 1996; 53(4): 269-275, doi: 10.1136/oem.53.4.269, indexed in Pubmed: 8664966.

32. Puttfarken T. Causes and circumstances of deaths of Polish seafarers during seavoyages. J Travel Med. 1996; 3: 91-95, doi: 10.1111/j.1467-8365.1981.tb00741.x.

33. Larsson $T$, Lindquist $C$. Traumatic fatalities among Swedish seafarers 1984-1988. Safety Science. 1992; 15(3): 173-182, doi: 10.1016/0925-7535(92)90003-i.

34. Mahdi SS, Amenta F. Eighty years of CIRM. A journey of commitment and dedication in providing maritime medical assistance. Int Marit Health. 2016; 67(4): 187-195, doi: 10.5603/IMH.2016.0036, indexed in Pubmed: 28009394.

35. WHO. International Classification of Disease, Tenth Edition. 2011, pp. 1-195.

36. Oldenburg M. Risk of cardiovascular diseases in seafarers. Int Marit Health. 2014; 65(2): 53-57, doi: 10.5603/IMH.2014.0012, indexed in Pubmed: 25231325.

37. Oldenburg M, Baur X, Schlaich C. Cardiovascular diseases in modern maritime industry. Int Marit Health. 2010; 61(3): 101-106, indexed in Pubmed: 21154295.

38. Oldenburg M, Jensen HJ, Lucas D, et al. Stress and Strain among Seafarers Related to the Occupational Groups. Int J Environ Res Public Health. 2019; 16(7), doi: 10.3390/ijerph16071153, indexed in Pubmed: 30935082.

39. Tu M, Jepsen JR. Hypertension among Danish seafarers. Int Marit Health. 2016; 67(4): 196-204, doi: 10.5603/IMH.2016.0037, indexed in Pubmed: 28009392.

40. Review C. CLINICIAN'S CORNER Value and Limitations of Chest Pain History. Heal. (San Fr). 2006; 294(20): 57-58. 